\title{
Os servizos de orientación na educación infantil e primaria en Galicia: xénese, implantación e evolución
}

\author{
School counseling services in early childhood and primary education in Galicia: origin, \\ implementation and evolution
}

\author{
Neves Arza, Mar Rodríguez \\ Facultade de Ciencias da Educación. Universidade da Coruña.
}

\begin{abstract}
Resumen
Nesta comunicación analízase o sistema de orientación na educación infantil e primaria en Galicia partindo dos motivos que están na orixe dos seus trazos diferenciais, caracterízase o proceso de implantación e a súa evolución. O motivo que explica a proposta é a promoción dunha orientación educativa, preventiva e integrada na actividade do centro, de aí a creación de servizos internos de orientación. O proceso de implantación foi demorada e precaria. Dende 2008 créanse departa- mentos de orientación compartidos co que se incrementa notablemente o número de centros con departamento de orientación. As políticas de axuste orzamentario que se están a levar a cabo dende vai uns anos, están a influir negativamente na súa consolidación. Palabras clave: Orientación educativa, Educación Infantil, Educación Primaria.
\end{abstract}

\begin{abstract}
We analyze the school counseling system in Galicia in early childhood and primary education taking into consideration the reasons that explain its peculiarities and describing the process of implementation and evolution of these services. The main reason to explain its design was the impulse of school counseling services essentially educational, preventive and integrated. Considering this, it was necessary to build inner school counseling services. The process of implementation was delayed and precarious. In 2008 the creation of shared school counseling departments significantly increased the number of these services. Recently, the policy of budget cuts in education is negatively influencing key conditions.
\end{abstract}

Keywords: School counseling, early childhood education, primary education

\section{Os servizos de orientación na educación infantil e primaria en Galicia}

Os servizos de orientación están vinculados aos procesos de modernización dos sistemas escolares. Á par que se democratizaban os sistemas educativos e se abría o espectro de grupos sociais e persoas aos que atendían (Viñao 2006), incluíronse profesionais, tarefas e servizos que combinaban dúas tarefas conflitivas. En primeiro lugar, a clasificación de suxeitos a través do diagnóstico e, en segundo lugar, a súa mellora educativa poñendo en marcha diversas estratexias para promover ao alumnado con problemas dentro do sistema (Rodríguez Romero, 1997). A partir destas orixes os servizos de orientación fóronse convertendo nunha estrutura complexa, con funcións diversificadas e ampliadas que combina o traballo de diversos profesionais (Santana Vega, 2007).

En 1998 a administración educativa galega completa o modelo institucional de orientación a través do decreto 120/1998 e da orde do 24 de xullo de 1998. Para a educación infantil e primaria créanse departamentos de orientación nos centros de 12 ou máis unidades. Os centros de menor tamaño adscríbense a departamentos doutros centros que poden ser de primaria ou de secundaria. Deste xeito, Galicia foi pioneira na implantación de servizos de orientación nos centros das primeiras etapas do ensino. Outra das novidades é a configuración dos servizos externos, denominados Equipos de Orientación Específicos (EOES), sendo as súas peculiaridades o seu ámbito de intervención e a súa especialización. En cada provincia crease un EOE que atende a todos os centros de ensino non universitaria da provincia. Entre os seus membros figuran un especialista en cada un dos seguintes ámbitos: orientación profesional, sobredotación, discapacidades motóricas, discapacidades sensoriais, trastornos do desenvolvemento e trastornos de conduta. As súas funcións céntranse, preferentemente no asesoramento e apoio especializado aos departamentos de orientación, sobre todo na avaliación psicopedagóxica e na elaboración de recursos e programas de intervención.

\section{Obxectivos}

Esta comunicación sintetiza os resultados dunha investigación realizada en 2008 patrocinada polo CIDE, dirixida pola profesora Consuelo Vélaz de Medrano e realizada en seis Comunidades Autónomas ${ }^{1}$. A nosa intención é analizar as razóns do modelo de orientación, describir a súa posta en marcha e posterior evolución no ámbito do ensino infantil e primario. Os obxectivos son:

a) Examinar os motivos que levaron a administración educativa galega a optar polo modelo de orientación elixido en educación infantil e primaria.

\footnotetext{
${ }^{1}$ Deseño de políticas públicas sobre orientación e apoio á escola: análise comparado nas Comunidades Autónomas que modificaron o sistema LOGSE. Financiada por el entonces CIDE, ahora IFIIE (Instituto de Formación del Profesorado, Investigación e Innovación Educativa) (Ministerio de Educación). 2007-2008.
} 
b) Analizar o proceso de implantación dos servizos de orientación en ambas as dúas etapas.

c) Describir a evolución dos servizos de orientación en educación infantil e primaria.

\section{Método}

O estudo de caso, realizado no marco da investigación mencionada, realizouse seguindo dúas liñas estratéxicas: a análise de documentos e o traballo de campo. Deste último, para os resultados aquí presentados, vanse aproveitar os datos procedentes de dúas entrevistas a expertos. A entrevista a expertos é unha modalidade de entrevista semiestruturada. Sen descoidar o guión previamente deseñado intentouse dar liberdade aos informantes claves. As transcricións das entrevistas mostran que foi posible dar cabida ao xeito particular de falar do entrevistado/a respecto dos asuntos incluídos no guión e de incluír algún tema importante dende o punto de vista do informante. Realizáronse dúas entrevistas a expertos cun total de tres informantes. Na entrevista coa responsable en 2008, a Directora Xeral de Innovación e Ordenación Educativa, incorporouse a Subdirectora Xeral. A existencia de dúas informantes na segunda entrevista non estaba prevista. A incorporación da Subdirectora Xeral, foi unha decisión da Directora Xeral por mor do seu coñecemento e experiencia na temática.

A análise de documentos foi unha técnica aplicada de modo recorrente para apoiar os testemuños dos informantes, xa fosen obtidos estes mediante entrevista ou cuestionario. É unha técnica apropiada para obter información retrospectiva (Walker, 1989) que permite contextualizar o alcance das medidas tomadas en materia de orientación. No presente estudo recompilouse textos de carácter normativo, informes de investigación sobre a orientación en Galicia e documentación estatística sobre evolución de indicadores socio-demográficos e educativos. Para a análise de documentos aplicamos unha clase de inferencia denominada "que é" (Gerbner, 1969) que permite a selección dun fenómeno ou dun tema e a súa clasificación en aspectos, compoñentes ou tópicos. Este tipo de inferencia proporciona concepcións comúns acerca dos fenómenos ou temas e configura coñecemento compartido.

\section{Resultados}

\section{Referentes e criterios nos que se apoia o sistema de orientación e á escola en infantil e primaria}

Para as etapas de infantil e primaria, debatíanse dúas posibilidades: manter os servizos externos incrementando o seu número ou optar, ao igual que en secundaria, por servizos internos. Finalmente, decidiuse crear un sistema de orientación interno apoiado por especialistas externos para casos moi concretos e con funcións moi delimitadas que non se solapasen coas dos servizos internos. Tratábase de conxugar a mellor decisión dende o punto de vista técnico e a viabilidade económica desta. Esta decisión foi precedida dun estudo comparativo dos servizos de orientación nos países da Unión Europea, segundo declaracións do exconselleiro (E1).
Os motivos que explican esta opción son, segundo o responsable político do deseño e implantación do sistema, de diversa natureza: a aposta polos servizos internos apoiada na convicción de que permitiría superar algúns dos inconvintes dos servizos externos; sobre todo pretendíase a promoción dunha acción orientadora educativa e integrada na actividade cotiá dos centros; dar unha resposta máis axeitada ás características de dispersión xeográfica dos centros e da complicada orografía que dificultaban os desprazamentos; estender os beneficios dos servizos internos aos centros que escalarizaban a alumnado de infantil e primaria, rompendo así o trato desigual que significaba a implantación de servizos internos unicamente nas etapas de educación secundaria; adoptar un modelo máis acorde coas tendencias estudadas nos sistemas de orientación dos países europeos; evitar a duplicación e o solapamento de funcións entre os servizos externos e internos; aproveitar o numeroso grupo de titulados en psicoloxía e pedagoxía existentes entre os mestres que podían asumir tarefas especializadas de orientación; os recursos económicos, tratábase de conciliar a mellor decisión técnica cos recursos dispoñibles.

\section{Xestión e xeralización do novo sistema}

En canto á difusión do cambio na comunidade educativa, pode dicirse que a Consellería articulou un tímido plan de difusión do cambio de estrutura, a través de publicacións oficiais. En consecuencia, non houbo un esforzo comprometido por comunicar aos centros e o profesorado as posibilidades que ofrecía o novo servizo e os novos profesionais.

Respecto da xeneralización dos servizos, realizouse de xeito progresivo dende o curso 1998-1999 e concluíuse no curso 2000-2001. Neste curso dispoñían de departamentos de orientación todos os Institutos de Educación Secundaria (IES), os Centros Públicos Integrados (CPI) e os Colexios de Educación Infantil e Primaria (CEIP) de 12 ou máis unidades (Xunta de Galicia, 2001). Os Colexios de Educación Infantil e/ou Primaria de menos de 12 unidades e as Escolas de Educación Infantil adscribíronse a un centro da zona que tanto podía ser un IES, un CEIP ou un CPI.

A adscrición dos centros de infantil e primaria a un departamento de orientación doutro centro presentou algunhas disfuncións, potenciadas, sobre todo nos primeiros anos, polo número de centros adscritos e pola dispersión xeográfica destes. Tamén hai que sinalar certas disfuncións que facían a adscrición moi pouco operativa.

En primeiro lugar, a normativa non contemplou, nin tempos, nin canles organizativo-institucionais necesarias para a integración do orientador/a nos centros adscritos. Estas carencias, xunto co tamaño e número dos centros adscritos, dificultaron o desenvolvemento dun traballo integrado na actividade educativa do centro e en colaboración co profesorado. Como manifestan algúns dos informantes "o orientador/a non ía ao centro" (E2, DX). Desta forma e dependendo do número de unidades e do número de centros adscritos cumpríanse todas as desvantaxes propias dun servizo externo. 
Os criterios de adscrición que se utilizaron foron os relativos ao número de alumnos/ás e de unidades en cada centro. Ademais priorizábase a adscrición de infantil aos centros de primaria e dos centros de primaria a secundaria nos que o alumnado, previsiblemente e por pertencer á mesma zona educativa, ía continuar a súa escolarización. A medida que se implantaban máis departamentos de orientación diminuía o número de centros adscritos e melloraba a atención aos centros.

En segundo lugar, a adscrición de centros de infantil e primaria aos institutos de educación secundaria ampliou considerablemente as funcións dos orientadores que abranguían na súa actuación etapas educativas radicalmente diferentes, dende infantil ata o bacharelato. De novo son os orientadores/ás de secundaria (GD3), xusto os que se viron co problema, os que sinalan a dificultade de ter que atender a varios centros con etapas e problemáticas moi diferentes.

En terceiro lugar, a adscrición non garantía a orientación nas primeiras etapas de escolarización, rompendo así con algúns dos principios que se asumían para o sistema de orientación: a idea dunha orientación continúa e preventiva, presente en todas as etapas educativas. Desta forma e como xa sinalamos, os propósitos educativos e preventivos do modelo quedaban limitados ao quedar desatendida a etapa máis importante para anticiparse aos problemas e potenciar o desenvolvemento do alumnado.

A implantación de departamentos de orientación e dos servizos externos, Equipos de Orientación Específicos (EOE), iniciouse no curso 1998-1999. A rede de departamentos de orientación construíuse de forma progresiva e concluíuse no curso 2001-2002, ao final do proceso tódolos centros que escolarizaban alumnado de secundaria tiñan departamento de orientación; os centros de infantil e/ou primaria con departamento de orientación eran 243 (Consellería de Educación, 2002). No que respecta aos EOE, creáronse catro un por cada provincia. Cada un dispoñía de oito especialistas, ascendendo o número total a 32. Non obstante, no ano 2001-2002 non se dotaran todas as prazas previstas. Na territorialización e dotación de persoal dos EOE non se tiveron en conta as diferenzas existentes na poboación escolar das catro provincias. Independentemente desta circunstancia, que condiciona as posibilidades de intervención dos EOEs e que esixe unha maior dotación en función do volume de poboación a atender, optouse por equipos co mesmo número de profesionais e coa provincia como sector de intervención.

\section{Evolución da provisión de servizos de orientación en educación infantil e primaria}

O principal cambio prodúcese no curso 2007- 2008 coa creación de departamentos de orientación compartidos nos centros de 6 a 11 unidades. Os centros de menos de 6 unidades adscríbense a un departamento de orientación dun CEIP ${ }^{2}$. A ampliación do número de

\footnotetext{
2 Estos cambios foron introducidos pola Circular 18/2007 das Direccións Xerais de Ordenación e Innovación Educativa e de Formación Profesional e Ensinanzas Especiais pola que se ditan instrucións para inifiar as actuacións e establecer as
}

departamentos superou algunhas das disfuncións do sistema de adscrición de centros: reduce a ratio de unidades/ alumnado que atenden, establecese o tempo de permanencia do orientador en cada centro e suprimese a adscrición de centros de infantil e primaria aos departamentos dos centros de secundaria, co que tamén se mellora a organización dos departamentos desta etapa, que só van intervir nas etapas da educación secundaria.

Coa creación de departamentos de orientación compartidos, a rede de orientación para os centros de educación infantil e /ou primaria queda configurada como segue (Consellería de Educación 2008):

a) Os centros de 12 ou máis unidades dispoñen de departamento de orientación no propio centro. Dependendo da realidade da zona poden ter centros adscritos.

b) Os centros de 6 a 11 unidades dispoñen de departamento de orientación compartido entre dous ou máis centros. Neste caso o orientador reparte a súa xornada laboral nos centros que comparten departamento e, se os hai, tamén nos centros adscritos.

c) Os centros con cinco unidades ou menos adscríbense a un departamento de orientación doutro centro.

Con esta modificación a composición dos departamentos de orientación compartidos quedou como segue: persoa que exerce a xefatura do departamento, persoas coordinadoras do ciclo, profesor/a de pedagoxía terapéutica, un especialista en audición e linguaxe, persoa coordinadora de educación infantil, persoa responsable da orientación nos centros adscritos, en caso de que os houbese.

Debido á creación dos departamentos de orientación compartidos, entre os curso 2007-2008 e 2009-2010, produciuse un notable incremento no número de centros con departamento de orientación. Segundo datos da Consellería de Educación (2008) no curso 2009-2010, o 45\% dos centros (390) dispoñía de departamento de orientación, o 13\% conta con departamento compartido e o 42\% están adscritos a un departamento doutro centro.

Outra das melloras introducidas foi que os centros que escolarizan a alumnado de infantil e/ou primaria deixan de adscribirse a centros de secundaria.

No que respecta aos EOE, nas provincias de maior poboación, A Coruña e Pontevedra, dotáronse cun especialista máis en trastornos de conduta.

\section{Discusión}

Os dous eixos que organizan o desenvolvemento da nova estrutura son: "a case xeneralización do apoio interno, a redefinición do apoio externo,". Por un lado, xeneralízase a implantación de servizos internos de orientación nos centros de infantil e primaria, aínda que ata 2007 só para os de máis de 12 unidades. Polo outro, abórdase a redefinición dos servizos externos mediante a especialización dos seus membros, a concentración dun único servizo en cada provincia -ata un total de catro- e a

accións prioritarias dos servizos de orientación educativa e profesional das ensinanzas escolares de Galicia. 
ampliación das súas actuacións a todas as etapas do ensino non universitario.

A planificación da rede de servizos de orientación non se baseou nas características demográficas e territoriais de Galicia. No período estudado produciuse unha perda continua de poboación escolar coa conseguinte redución do número de alumnado e de centros educativos . Esta circunstancia, allea á política educativa, contribuíu ao descenso do número de centros adscritos aos departamentos de orientación. Unha vez máis convén indicar que sería necesario contar con datos demográficos por provincias para ter evidencias máis concretas.

A creación de departamentos de orientación unicamente nos centros de 12 ou máis unidades non foi unha resposta axeitada a unha das características máis sobresaíntes da rede de centros: a súa dispersión xeográfica e o seu tamaño; sobre todo nas provincias de Lugo e Ourense. A dotación de profesorado de apoio (pedagoxía terapéutica e audición e linguaxe) non respondeu ás necesidades do sistema. O descenso da poboación escolar e a redución de número de centros, especialmente aqueles con menos unidades e situados en poboacións rurais, contribuíu indirectamente ao descenso da ratio de centros adscritos que tiñan asignados algúns departamentos de orientación. Un cambio relevante que introduciu melloras innegables foi a creación de departamentos compartidos, co que houbo unha maior dotación de recursos humanos e se melloraron as condicións en canto á ratio de alumnado por departamento de orientación.

No que respecta aos EOE, nas provincias da Coruña e Pontevedra, as de maior poboación, dotáronse cun especialista máis en trastornos de conduta.

Ao final do proceso de implantación dos servizos de orientación creáranse un total 243 departamentos. A recolocación dos profesionais dos 35 EPSAs existentes achegou 52 psicólogos, 55 pedagogos, 40 especialistas en audición e linguaxe e 4 asistentes sociais; é dicir, un total de 151 profesionais. En consecuencia, tanto a achega de profesionais dos EPSAs, 151, coma a conversión de 243 mestres/ás en orientadores minoraron, sen dúbida, a partida presupostaria reservada a persoal.

Os recursos económicos destinados á orientación foron evidentemente insuficientes. Como manifestou o responsable político do deseño e implantación do sistema de orientación galego, tratábase de conciliar as mellores decisións técnicas cos recursos dispoñibles. Esta restrición de recursos condicionou a ampliación da rede de departamentos de orientación aos centros de infantil e primaria de menos de 12 unidades e aos centros de educación especial, favoreceu o recurso á adscrición dos centros e limitou a creación de servizos externos e a súa dotación de profesionais sen considerar o volume da poboación a atender. A cicatería nos recursos orzamentarios tamén pode explicar o lento calendario de implantación dos departamentos de orientación, que non chegaría a completarse ata o curso 2001-2002. Parece evidente, que, sen contar cos recursos económicos necesarios, a orientación non constituíu unha prioridade da política educativa. Como tampouco o foi o apoio aos centros educativos do medio rural, que en relación coa orientación foron os máis desatendidos.
Tras décadas de monotonía política, o relevo nas eleccións autonómicas do 2004 impulsou o reaxuste dalgúns aspectos como: a racionalización da rede de orientación, o incremento dos DO en centros de infantil e primaria e dos especialistas de audición e linguaxe, e a elaboración e difusión de materiais para a atención á diversidade e a acción titorial.

A aplicación de medidas de austeridad nos últimos anos están a limitar o orzamento destinado á Educación e consecuentemente ó sistema de orientación. Como veñen denunciando os sindicatos e os profesionais non se están a cubrir as vacantes de departamentos de orientación ${ }^{3}$, co que se reduce o número de orientadores e de centros con departamento de orientación, á vez empeoran algunhas das condicións necesarias para un óptimo desenvolvemento dos servizos de orientación.

\section{Referencias}

Consellería de Educación e Ordenación Universitaria (2002). A orientación educativa e profesional. Estructura organizativa dos servicios de orientación. Santiago de Compostela: Xunta de Galicia.

Consellería de Educación (2008). Rede da orientación educativa en Galicia. Santiago de Compostela: Xunta de Galicia.

Decreto 120/1998, do 23 de abril, polo que se regula a orientación educativa e profesional na Comunidade Autónoma de Galicia (DOG del 27 de abril de 1998).

Flick, U. (2004). Introducción a la investigación cualitativa. Madrid: Morata

Gerbner, G. (1969) "Towards cultural indicators: the analysis of mass mediated public message systems" en Gerbner, G. et Al. (Eds.) The analysis of communication content. New York, John Wiley and Sons, INC.

Orde do 24 de xullo de 1998 pola que se establece a organización e funcionamento da orientación educativa e profesional na Comunidade Autónoma de Galicia regulada polo Decreto120/1998 (DOG del 31/07/1998).

Rodríguez Romero María Mar (1997). La confluencia del asesoramiento y la orientación como prácticas de apoyo. En Rodicio, M. L. e González X. Actas del Simposium Hacia dónde camina la orientación. A Coruña: Universidade da Coruña.

Santana Vega, Lidia E. (2007). Orientación Educativa e intervención psicopedagógica. Cambian los tiempos, cambian las responsabilidades profesionales. Madrid: Ediciones Pirámide.

Stake, Robert E. (1998). Investigación con estudio de casos. Madrid: Morata.

Viñao Frago, A. Sistemas educativos, culturas escolares y reformas. Madrid: Morata.

\footnotetext{
${ }^{3}$ Desde 2008 a Administración Educativa non publicou datos relativos a rede de orientación. Polo tanto, non se dispoñen de datos oficiais.
} 